\title{
APRENDIZAGEM POR PARES: EXPERIÊNCIAS PARA O ENSINO DA DISCIPLINA DE HISTÓRIA A PARTIR DE DADOS APONTADOS PELO PROGRAMA INTERNACIONAL DE AVALIAÇÃO DE ESTUDANTES (PISA)
}

\section{ARTIGO ORIGINAL}

PASSOS, Rogério Duarte Fernandes dos ${ }^{1}$

PASSOS, Rogério Duarte Fernandes dos. Aprendizagem por pares: experiências para o ensino da disciplina de história a partir de dados apontados pelo programa internacional de avaliação de estudantes (PISA). Revista Científica Multidisciplinar Núcleo do Conhecimento. Ano 06, Ed. 07, Vol. 09, pp. 50-67. Julho de 2021. ISSN: 2448-0959, Link de acesso: https://www.nucleodoconhecimento.com.br/educacao/programa-internacional, DOI: 10.32749/nucleodoconhecimento.com.br/educacao/programa-internacional

\section{RESUMO}

Em breves abordagens e intuições de ordem metodológica qualitativa, o artigo objetiva retratar inicialmente algumas dificuldades da educação brasileira expostas a partir de dados apontados pelo Programa Internacional de Avaliação de Estudantes (PISA) - promovida pela Organização para a Cooperação e Desenvolvimento Econômico - indagando-se se a aprendizagem pode alcançar progressos pela superação de dificuldades organizacionais e, por conseguinte, seguindo-se em resposta, considerações sobre a metodologia da aprendizagem por pares como potencial contributo para a melhoria do ambiente educacional e do ensino da disciplina de História, somando-se ao tema reflexões de ordem pedagógica.

\footnotetext{
${ }^{1}$ Mestre em Direito Internacional pela Universidade Metodista de Piracicaba (UNIMEP) e Doutor em Educação pela Universidade Estadual de Campinas (UNICAMP).
}

RC: 91806

Disponível em: https://www.nucleodoconhecimento.com.br/educacao/programainternacional 
Palavras-chave: Avaliação da educação brasileira, Ensino de História, Aprendizagem por pares, Reflexão pedagógica.

\section{INTRODUÇÃO}

Realizado a cada três anos, o diagnóstico do Programa Internacional de Avaliação de Estudantes (Programme for International Student Assessment, PISA), promovido pela Organização para a Cooperação e Desenvolvimento Econômico (OCDE, Organization for Economic Cooperation and Development) ${ }^{[2]}$ - entidade criada em 1961 e que se tornou um fórum político e de articulação dos países mais ricos e desenvolvidos do mundo - adquiriu caráter mainstream ${ }^{[3]}$ no âmbito das discussões sobre educação.

Segundo Schleicher (2018), institucionalmente com o intuito de auxiliar decisores públicos e formuladores de políticas a redirecionar o olhar ao sistema educacional e oferecer dados para que as ações no setor possam melhor ser alicerçadas, o PISA promove avaliação em diferentes países sobre ciências, matemática e leitura a partir de questões submetidas aos alunos e alunas, bem como por meio de perguntas direcionadas a pais e educadores.

Sobre o PISA, nos esclarece o Instituto Nacional de Estudos Pedagógicos Anísio Teixeira (INEP) (INSTITUTO NACIONAL DE ESTUDOS PEDAGÓGICOS ANÍSIO TEIXEIRA, 2019), que o exame oferece informações de estudantes na faixa etária de quinze anos - inseridos, portanto, no ínterim da educação básica - trazendo, um conjunto de antecedentes, ações, condições e circunstâncias relacionadas à aprendizagem dentro e fora do ambiente escolar, e desde a primeira edição, no ano 2000 - a qual, desde então, o Brasil participa - há um aumento de países e economias em análise, permitindo também avaliação comparativa e compartilhamento de competências e habilidades em favor de qualidade e equidade no setor. 
Como bem aquilatado por Viggiano (2019), a última avaliação do PISA, realizada em 2018 e com dados divulgados em 2019, embora revelando algum progresso brasileiro, expõe uma situação complexa e distante do ideal, trazendo em bases estruturais problemas relacionados a desigualdades sociais, acesso com a já mencionada equidade, uso de novas tecnologias e técnicas para a aprendizagem, bem como tribulações do ambiente escolar somados ao bullying, aliado ao quadro de desestímulo e desrespeito nesse espaço de construção individual e coletiva.

Ex positis, considerando que o uso de novas técnicas de aprendizagem colaciona-se em um dos problemas que o PISA apontou na educação brasileira, neste texto aduzir-se-á brevemente o aporte que a metodologia da aprendizagem por pares (AP, instrução entre pares, peer learning, peer-to-peer learning) potencialmente pode oferecer para 0 aperfeiçoamento pessoal de competências e habilidades, representando, igualmente, um breve contributo para o desenvolvimento do ambiente educacional e, em especial, para o ensino de História em espaços de educação básica.

Entrementes, em guisa de introdução, vale ainda mencionar o diagnóstico social de Joanilho (2009, p. 11-12), acrescentando que no bojo do conhecimento histórico o avanço não se liga tão somente ao aprimoramento, e sim, ao ínterim de mudanças sociais alicerçadas ao momento presente e em transformações de sua prática social e científica, clamando-nos para superar o sentimento de senso comum que a passagem do tempo conduz inexoravelmente ao progresso e em direção de concepções que em essência seriam superiores às do passado, uma vez que diferentes gerações possuem dinâmicas próprias e práticas distintas, impactando e transformando as ações da respectiva sociedade no instante e espaço em que são vividas e na ciência que então é produzida e lhe é correspectiva. 


\section{O ENSINO DE HISTÓRIA}

A palavra história tem origem e base etimológica no grego antigo (ібторía), podendo significar investigação e relato, pesquisa de documentos escritos ou não, costumes, discursos, falas e resquícios arqueológicos. Na definição do filólogo Francisco da Silveira Bueno (1898-1989), ao lado do conceito de conto, tem-se a narrativa e narração de fatos da humanidade (BUENO, 2007, p. 412), e, como nos ensinam Ferreira; Fernandes (2005, p. 3-7), alcançando a ideia de testemunho, busca a compreensão integrada de eventos pretéritos, considerando a percepção do tempo substanciada em elementos do passado, presente e futuro, bem como de distintos lugares e épocas e com diferentes medidas, sem desprezo à trajetória única e individual de cada um dos seres humanos.

$\mathrm{Na}$ condição de disciplina curricular do sistema formal de educação, por sua vez o ensino de História relaciona-se com a necessidade premente do ser humano em alcançar as próprias raízes e respostas acerca do significado e de melhor compreensão do momento presente. Nesse processo, a análise das provas, dos indícios ou despojos que trazem sorrateiro e precário conduto vivificador de sobrevida ao passado, pelo estudo histórico se mostra não definitivamente incauto ante as circunstâncias paradoxais que Ihes são de forma impávida e heroicamente retroalimentadas, não raro, no trabalho de um único indivíduo-historiador, que em vida, mostra-se capaz de reagir à ignávia de dar cabo ao finito, posicionando-se no embate social como a personagem que não pediu licença para jogar, mas que, fazendo-o, busca derrubar as peças da memória afetiva coletiva, institucional e burocraticamente edificada.

Dito isso, no âmbito ocidental os estudos de História caminharam e se alicerçaram em direção de maior dimensão científica pelo legado, obra e pensamento de significativos expoentes da cultura, como Heródoto (485 a.C. - 425 a.C.) - o "pai da história" - no Século V a.C. na Grécia Antiga, bem como pelo trabalho do pesquisador Tucídides (ca. 460 a.C. - ca. 400 a.C.), general ateniense também 
deste período, autor de A História da Guerra do Peloponeso, travada entre a Liga do Peloponeso, liderada por Esparta, e a Liga de Delos, liderada por Atenas, no mesmo Século V a.C. Por sinal, documentando e vivenciando o conflito, como analisado por Crane (1998), Tucídides mostra-se capaz de sistematizar um trabalho com considerações atinentes a uma cultura grega compartilhada, com subcategorias concorrentes de etnia e laços familiares (CRANE, 1998), de forma que no universo da Hélade, nesse ínterim, vale ainda mencionar contribuições igualmente importantes de Xenofonte (ca. 430-355) por meio de sua obra Helênicas, na qual prosseguiu com os estudos da Guerra do Peloponeso aproximadamente entre 411 a.C. e 362 a.C.

Nesse ínterim, por oportuno, de forma semelhante ao surgimento da Filosofia enquanto conhecimento organizado, como bem coloca Frazão (2019), Tucídides contribui para a sistematização da História em direção da superação de fábulas e anedotas, documentando o passado e buscando dele alcançar maior compreensão, sem se deixar impressionar pelo "primeiro informante" e mesmo pelas impressões pessoais, mas colimando outros testemunhos e a eles impondo um julgamento severo e crítico, adicionado às suas experiências, em direção à construção de um verdadeiro método.

No Brasil, com contribuições e impulso de Francisco Adolfo de Varnhagen - o Visconde de Porto Seguro (1816-1878), apelidado de "o Heródoto brasileiro" historiador com influência da "escola científica alemã" - que em seu bojo trouxe grande preocupação com o levantamento de fontes originais em pesquisa (BORGES, 1993, p. 74) - o estudo da História enquanto disciplina escolar remonta ao Século XIX, abrangendo o período imperial e o início da República, e trazendo a inspiração do modelo francês, privilegia feitos e heróis do país - bem como o cultivo à pátria - em projeto de formação cultural das elites (PORTAL EDUCAÇÃO, s. d.).

Considerando o ensino de História como disciplina escolar, no interior da versão homologada em 2017 e com a parte do ensino médio homologada em 14 de 
Dezembro de 2018 pelo Ministério da Educação (MEC) da Base Nacional Curricular Comum (BNCC) - justamente o documento elaborado pelo MEC que assinala o direito às aprendizagens essenciais, currículos e conteúdos mínimos em escolas públicas e particulares no âmbito do ensino infantil, fundamental e médio (BASE NACIONAL CURRICULAR COMUM, p. 13) - em cumprimento ao inciso IV do artigo 9o da Lei ํo 9394/1996 (Lei de Diretrizes e Bases da Educação Nacional, LDB) (BRASIL, 1996), estrutura-se uma ferramenta para melhor percepção das experiências das sociedades humanas onde o indivíduo se insere, substanciando diretrizes para a condução do componente curricular em favor de um contexto de autonomia, responsabilidade e exercício da cidadania.

Por oportuno, com importantes repercussões no ensino de história, a BNCC

Reconhece, assim, que a Educação Básica deve visar à formação e ao desenvolvimento humano global, o que implica compreender a complexidade e a não linearidade desse desenvolvimento, rompendo com visões reducionistas que privilegiam ou a dimensão intelectual (cognitiva) ou a dimensão afetiva (BASE NACIONAL CURRICULAR COMUM, 2018, p. 12).

Para o alcance dessa missão, no momento contemporâneo, no mesmo sentido é pertinente tomar em conta o diagnóstico de Altoé (2019), por meio do qual a história

não se restringe apenas a datas importantes ou personagens marcantes, sejam heróis ou vilões. Para se chegar a um dia crucial ou mesmo entender ações que influenciaram a vida da população é necessário compreender processos que envolvem grupos humanos ligados ao evento em questão (ALTOE, 2019).

Feitas essas ponderações, podemos localizar a metodologia da AP como uma ferramenta pedagógica apta a oferecer a sua contribuição para o ensino, relacionamento e assimilação dos conteúdos da disciplina de História no ambiente da sala de aula, uma vez que pode contemplar aprendizagens obtidas em múltiplos e diferentes contextos, aproveitando, inclusive, os alcançados em outros componentes curriculares e espaços, agregando valor e impulso ao progresso do próprio ambiente educacional. 


\section{A METODOLOGIA DA APRENDIZAGEM POR PARES}

Em vinte e seis anos de prática docente, observamos que em vários momentos, espontaneamente alunas e alunos sentam-se na sala de aula em duplas para se auxiliarem nas atividades pedagógicas, e, em outros, quando pensamos que estão se distraindo, na verdade estão debatendo o assunto estudado, de forma que aquele estudante que melhor compreendeu a questão compartilha de imediato a sua percepção com os demais.

Por sinal, supõe-se que o fenômeno não seja novo, uma vez que possivelmente ocorreu nas salas de aula do Brasil e do mundo nas cinco primeiras décadas do Século XX em face das antigas carteiras escolares - com espaço para caneta tinteiro e mata borrão - cujo formato e arquitetura proporcionava que os estudantes se sentassem em dupla. E novamente remontando à nossa prática docente, é comum ver alunas e alunos, por motivação própria, unirem as carteiras individuais para a palestra do professor e praticarem as demais atividades pedagógicas.

Em observação a estes contextos que o nosso interesse pela AP se aguçou, no que podemos concebê-la como uma metodologia ativa de aprendizagem em contextos formais ou informais de educação, na qual alunos interagem, e de forma cooperativa e auto-organizada, comprometem-se dinamicamente com os conteúdos objeto de estudo, de maneira que aqueles que melhor o assimilaram e com ele se relacionaram, podem tornar-se agentes de monitoria, compartilhamento, (des)construção e propagação de saberes, contextualizando cognitivamente dados e informações para que em espaços de convivência reduzida e particular, alcancem maior sentido e significado.

Bebendo em fontes diversas e inspirando-se no legado de experimentação e verificação do pedagogo e filósofo John Dewey (1859-1952) - sobretudo, em conceber a educação como ato ativo e construtivo, com o compartilhamento e renovação de experiências - atribui-se essa sistematização no ensino superior - e 
mesmo a criação mais organizada dela ou a sua maior especificação e instrumentalização em contextos previamente estruturados e planejados - a Eric Mazur, professor neerlandês de Física na Universidade de Harvard, em Cambridge, na área metropolitana de Boston, no Estado norte-americano de Massachusetts, quando em meados de 1991, denominando a AP de instrução por pares (peer instruction), desenvolveu prática na qual os estudantes são envolvidos em atividades que exigem de cada um deles a aplicação dos principais conceitos trabalhados nas aulas, compartilhando-os, em seguida, aos colegas (CROUCH; MAZUR, 2001, p. 970). No balanço dos dez anos dessa metodologia, se expôs que ao contrário das tradicionais perguntas da aula em forma de palestra, que envolvem apenas alguns alunos, trazendo a possibilidade de motivação aos estudantes, há um processo com questionamento mais estruturado, apto a abranger todos os eles, em ação potencialmente útil para turmas grandes ou pequenas (CROUCH; MAZUR, 2001, p. 970).

Acerca de vantagens e desvantagens da AP, o tema se insere na autonomia do professor em refletir sua prática pedagógica e, mesmo, na liberdade de cátedra contemplada nos incisos II e III do artigo $2^{\circ}$ da LDB (BRASIL, 1996) - na qual o docente deve observar as vicissitudes individuais dos alunos e o contexto orgânico das salas de aula sob sua responsabilidade, perquirindo e diagnosticando de forma acurada as necessidades mais adequadas que deverão ser direcionadas e conduzidas para os momentos de aprendizagem.

Como pontos desfavoráveis da aplicação da AP, podemos apontar a difusão de informações não afiançáveis ou confiáveis - proporcionadas, inclusive, pelo uso de dispositivos eletrônicos móveis instantâneos - difundindo objeto filosófico "cognoscível" falso e não verificável (fake news), em dados que epistemologicamente não são condizentes com a face solene e de entendimento que deveria se revestir a escola. Ademais, argumentar-se-ia que alguns desses conteúdos seriam expressos em uma linguagem não compatível com a instrução escolar e em viés excessivamente coloquial, sem rigor ético e científico. No mesmo 
esteio é possível ter um ambiente influenciado por estudantes imaturos e indisciplinados, desfocados com a melhoria pessoal e com o projeto pedagógico da escola, no que mereceriam atenção reestruturadora especial por meio de outras estratégias específicas.

Nesse sentido, inclusive, é possível argumentar que a responsabilidade pela oferta do conteúdo, mediação e planejamento das atividades pedagógicas seja de plena e total responsabilidade dos docentes, no que a AP prejudicaria a apreensão e assimilação.

Como possíveis vantagens, podemos arguir a posição de igualdade (de pares), que nesse ambiente se estabelece entre os estudantes - inclusive no uso da linguagem e decodificação de mensagens e informações - bem como a valorização do lugar de fala de alunas e alunos na condição de sujeitos da própria formação e história. Acresça-se que o desenvolvimento de competências ${ }^{[4]}$ e habilidades ${ }^{[5]}$ na expressão escrita, falada - e, consequentemente, emocional - poderão receber ganhos, permitindo maior desenvoltura e segurança em grupos maiores ou menores de estudantes, de acordo com a sensibilidade e necessidade da ocasião pedagógica.

Cotejando a AP como uma ferramenta, uma metodologia que possa contribuir para a melhoria dos resultados da educação brasileira, de sua qualidade, e principalmente, como contribuição para o ensino da disciplina de História, é possível alicerçar-se nas possibilidades de construção cognitiva apoiadas em diferentes correntes epistemológicas, filosóficas, pedagógicas, e da própria psicologia, capazes de proporcionar a diversificação de estratégias em favor da promoção de pluralidade de linguagens no ambiente escolar.

Ademais, em guisa de contextualização ao tema, tomemos as lições de Schmidt (2009), nas quais se tem a educação como ferramenta de uma cultura compartilhada e conectada, portanto, com influências mútuas entre educação e a própria cultura, nessa última sugestionada pelas práticas das novas gerações, que aprendem e adaptam conhecimentos das anteriores. Nesse sentido, adquirir e compartilhar 
conhecimentos são as motivações para se participar de uma comunidade que proporcione aprendizado, de forma que este se torne parte intrínseca de processos de inovação centrados no aluno (SCHMIDT, 2009).

Ainda que o trabalho deste último autor citado se volte igualmente à segurança construída no desenvolvimento de softwares, coteja-se a análise e avaliação das ações individuais de aprendizagem, capazes de estabelecer níveis de credibilidade nos conteúdos e informações pesquisadas e trabalhadas para afiançar qualidade, como são comuns nos espaços de economia digital, podendo-se materializar um resultado desse processo, mesmo que o mecanismo de recomendação interpessoal não se encaixe plenamente no mundo não virtual, pois que em tempo real não seja possível dimensionar a confiança a partir da indicação de um membro distante do círculo social (SCHMIDT, 2009).

Estabelecidas essas considerações em nível teórico, em nossa prática docente, por sua vez a AP se materializaram de forma básica, com a readequação da organização espacial da sala de aula, onde os alunos unem as carteiras para discutir os conteúdos recebidos e pesquisados, expondo-os em seguida por meio da expressão verbal e escrita nas distintas atividades que compõe o ínterim de avaliação escolar.

\section{A APRENDIZAGEM POR PARES COMO PROPOSTA DE MELHORIA DO ENSINO DE HISTÓRIA}

Podendo, inclusive, ser utilizada com redes sociais da rede mundial de computadores (Internet), com fóruns, ferramentas de tecnologias de informação e comunicação (TIC), plataformas da rede mundial de computadores ou no ambiente de educação não presencial, educação à distância $(\mathrm{EaD})$ e modelos híbridos entre ambos (blended learning) ${ }^{[6]}$, mobilizando diferentes linguagens, recursos dos próprios alunos e elementos da própria realidade vivenciada no presente, a AP insere-se como possibilidade de contribuição significativa para a melhoria do 
componente curricular de história e do próprio ambiente educacional, na medida em que permite o trabalho pedagógico com interdisciplinaridade em um espaço no qual o conhecimento, democraticamente, é fluido e coloca-se à disponibilidade de todos.

Sendo ferramenta pedagógica que potencialmente pode permitir atribuição de maior significado ao conhecimento, a AP é capaz de agregar valor às práticas docentes e proporcionar ganhos no ambiente escolar e no resultado da educação brasileira em avaliações internacionais, como no caso do PISA, no que reconhece-se, porém, que o mais importante e significativo é pensá-la no bojo de referenciais de qualidade em uma lógica que contemple a coerência e a coesão, a autonomia, a socialização, a profissionalização e a construção de uma cidadania ativa nos estudantes.

No âmbito do ensino de História, resgatando os referenciais teóricos adotados nesse texto, reitere-se a advertência de Joanilho (2009, p. 11-12), na qual o avanço histórico não se apoia apenas em aperfeiçoamento, mas em mudanças no presente e nas transformações que o alcançam com impactos em sociedade e ciência afastando o senso comum que a passagem de tempo conduz ao progresso e a um presente superior ao passado - a AP é um exercício criativo, desafiador para docentes e estudantes no intuito de proporcionar inovação no ambiente educacional em face da tradicional aula alicerçada no formato de palestra e uso da lousa.

Ademais, como igualmente destacado em Ferreira; Fernandes (2005, p. 3-7), tanto no ensino de História, como no processo educacional enquanto um todo, o ideal é privilegiar um tratamento integrado na relação de fatos pretéritos, relacionado, ao modo defendido por Altoé (2019), uma abordagem que não deve cotejar apenas datas, fatos e personagens importantes, porém, considerar em conjunto circunstâncias que impactaram grupos humanos inseridos nelas, de forma que a AP, mobilizando diferentes recursos que partem, especialmente dos próprios estudantes, pode agregar valor ao trabalho educacional de toda a comunidade escolar, potencialmente adicionando às práticas cotidianas elementos de autoconhecimento, 
gestão de conflitos, alteridade e diálogo, capazes de conduzir o estudante à resolução de problemas e ao enfrentamento de contextos novos em sua jornada.

No âmbito de uma educação que se quer holística - reiterando a advertência supracitada da BNCC em não praticarmos reducionismos - aludimos que nos fenômenos humanos, a complexidade envolvida desvela diferentes possibilidades, no que a percepção, sensibilidade e serenidade dos professores envolvidos no ato de ensinar, tutorar e compartilhar, sobretudo, em um período que revela uma educação que clama por acolhimento, afetividade, cooperação e convivencialidade, será deveras importante no reconhecimento das melhores estratégias, ações e metodologias para a eficaz concretização de seu trabalho.

Neste tópico, acresça-se a percepção de Viggiano (2019) na leitura dos dados expostos no relatório do PISA, dos quais extrai-se que a solidão, alcançando um quarto dos estudantes brasileiros, é ponto de relevância a ser considerado, pois os alunos, se sentindo isolados nas aulas, carecem dos atos de companheirismo e cooperação, tão requeridos para um ensino de qualidade.

Anísio Teixeira (1900-1971), eminente educador brasileiro cujo nome veio a batizar em 2001 o INEP, tendo dirigido-o entre 1952 e 1964, ainda no ano de 1953, pugnando pelos aspectos fundamentais de organização, liberdade, responsabilidade e autonomia, nos admoestou acerca da urgência de lançarmos um olhar de atenção à questão educacional com o uso de métodos lícitos e aconselháveis, sob a égide da aprovação do consenso e consciência profissional - bem como pela ciência educacional existente e pelas contribuições inovadoras de outros mestres autorizados - no que, havendo a necessidade de superação de um primeiro obstáculo de ordem legal, estrutural e de efetivação de garantia de recursos para a educação brasileira, surgiria a tarefa de triunfo sobre um segundo problema, esse estritamente de ordem profissional, a ter solução pelos educadores brasileiros,

(...) em um ambiente de liberdade e responsabilidade, de experimentação e verificação, de flexibilidade e descentralização,

RC: 91806

Disponível em: https://www.nucleodoconhecimento.com.br/educacao/programainternacional 
para que se crie a escola brasileira, diversificada pelas regiões, ajustada às condições locais, viva, flexível e elástica, com a só unidade de se sentir brasileira na variedade e pluralidade de suas formas. Este segundo problema é o problema para sempre irresolvido do melhoramento e aperfeiçoamento indefinidos das instituições escolares brasileiras. Para que se encaminhe, entretanto, a sua solução gradual e progressiva, é indispensável que se organize a liberdade de experimentar, tentar, ensaiar, verificar e progredir, na escola brasileira [ortografia então vigente da Língua Portuguesa].

Cientes que nosso processo cognitivo permanece em construção por meio da aprendizagem ao longo da vida, em exercício da máxima socrática de apenas sabermos que nada sabemos, devemos tomar axiologicamente a educação como dimensão privilegiada da cultura e do adiantamento moral, e mesmo, de sua gradativa substância enquanto campo de pesquisa social, de forma que essas são considerações de vulto a alicerçar nossas reflexões e práticas, no que cabe amplamente ao docente a reflexão de se utilizar - ou não - a possibilidade da AP.

\section{CONSIDERAÇÕES FINAIS}

No contexto da AP, as novas tecnologias podem se constituir em uma ferramenta de significativa contribuição para a educação brasileira e para o ensino de História e de outros componentes curriculares, inclusive considerando o seu potencial de experimentação, discussão e a decorrente edificação de meios e sensibilidades para a interpretação de dados, de fatos e, mesmo, de resolução de problemas. Permanece, porém, o imprescindível papel de envolvimento e mediação dos professores nessa missão, devendo estes prudentemente se responsabilizarem pela disciplina, pelos conhecimentos e pelas orientações oferecidas aos estudantes.

Considerando essa advertência, no parâmetro estabelecido no caput do artigo $1^{\circ}$ da LDB (BRASIL, 1996), não podemos olvidar do papel das famílias nesta jornada, que não devem delegar integralmente aos espaços de educação formal as noções básicas de sociabilidade, etiqueta e respeito ao próximo, no que a sua missão de célula formativa primeira do ser humano permanece evidente. Ademais é preciso reconhecer que os educadores precisam consumir bens culturais e refletir sobre a

RC: 91806

Disponível em: https://www.nucleodoconhecimento.com.br/educacao/programainternacional 
sua própria disciplina e prática pedagógica, algo que nem sempre se afigura plenamente possível, visto que a exigência de redução de custos das unidades escolares e o desenvolvimento das TIC, ao invés de proporcionar maior tempo disponível, delegaram funções administrativas e burocráticas ao próprio docente, tendo este que se dedicar a atividades, não raro, sem repercussão ou relação com o espectro estritamente pedagógico.

Tomando a assertiva de observar o passado de forma integrada a circunstâncias e fatos para analisar mais afincadamente o presente e melhor projetar, planejar o futuro, e, nesse desiderato, conjugando-se as novas tecnologias com as boas práticas de professores e alunos, ter-se-á o ambiente potencialmente propício para o alcance de um bom produto final na atividade educacional, de forma que a AP é uma possibilidade convidativa acrescentada ao ínterim educativo.

Em consequência a AP pode incentivar alunas e alunos a se motivarem - e se encorajarem - em direção à colaboração nas atividades pedagógicas, favorecendo a criação de um ambiente vibracional e energeticamente positivo para a produção e construção do conhecimento, possibilitando, até mesmo, o uso de outras metodologias, como a prática da chamada sala de aula invertida (flipped classroom), na qual os estudantes recebem previamente o material de estudo e o compartilham em diferentes atividades de ensino com demais colegas dentro e fora do ambiente escolar.

Sob a supervisão dos professores, a instrumentalização de metodologias colaborativas e ativas, centradas nos alunos - onde se deposita grandemente a confiança neles - podem amplamente ser utilizadas em vários componentes curriculares e disciplinas - contribuindo para a melhoria global do contexto educacional - não sendo diferente no ensino de História, cuja potencial prática, inclusive, pode ser instrumentalizada para a compreensão holística, ou mesmo, para a abordagem ou resolução de questões específicas do conteúdo. 
Ipso facto, na AP, faz-se necessário que os alunos abandonem a tradicional postura passiva e integrem-se com os assuntos lecionados e disponibilizados. Há um processo de verdadeira interação com o conteúdo, exigindo a sua presença e posicionamento diante do conhecimento. Exige-se mais que responsabilidade, senão, um verdadeiro comprometimento com a professora ou professor, com os colegas e com o aprendizado, no que, o papel ativo do estudante no processo educacional poderá, inclusive, evidenciar-se para o alcance de uma posição não apenas de mero replicador, mas de verdadeiro desconstrutor ou multiplicador do saber, em exercício solidário com os companheiros de jornada que eventualmente sintam-se isolados ou tenham dificuldades, ou que ainda queiram aprofundar-se nos diferentes campos de estudo. É possível crer que em alguns desses estudantes, até mesmo, soerguerá a vocação profissional para seguir a carreira docente, carente de novos quadros em nosso país.

Por suposto, no ensino e aprendizado da História enquanto componente curricular, são oportunas as lições da professora Vavy Pacheco Borges - uma das pioneiras no estabelecimento de um olhar sob o ponto de vista dos oprimidos na disciplina em nosso país - especialmente em recordar que há uma escolha do historiador acerca dos objetos que estuda a partir de suas circunstâncias concretas, pelos níveis, métodos, técnicas e conhecimentos disponíveis, bem como por seus interesses (BORGES, 1993, p. 65), no que acrescentamos que, de forma semelhante, esse processo se materializa em sala de aula e na tentativa de tornar o ensino de História um elemento vivo e "presente" por meio da AP.

Em ínterim contínuo, por meio da responsabilidade suscitada pela AP, espera-se haver contribuição para o estudante aperfeiçoar a administração de sua rotina e agenda disponível, melhor aproveitando a ocasião dos estudos - seja no próprio ambiente de sala de aula ou fora dele, e mesmo, nos demais espaços da escola recebendo inestimável lição para reflexão de sua práxis nas distintas demandas de sua vida. A competência de ter foco, estabelecer prioridades no momento dedicado aos estudos, não procrastinar o necessário (e o aprendizado e a construção 
pessoal), se planejar, se organizar e melhor conduzir o tempo disponível - em um período em que a passagem dele parece ser muito rápida e acelerada pelas TIC bem como o interregno despendido para a experiência gnosiológica com o universo, pode receber valiosa contribuição desse exercício de pertencimento e relacionamento ativo com o conhecimento.

Em ambiente colaborativo potencialmente proporcionado pela AP, a experiência cotidiana, no bojo de interdisciplinaridade - aliada aos conhecimentos já adquiridos em outros espaços de vivência e de exercício do pensamento crítico - somada à linguagem particular de cada um deles, ao contexto cultural e às possibilidades de exploração criativa dos alunos levado em conta nesta metodologia, da mesma forma, poderá permitir a identificação de parâmetros éticos na produção do saber, e, igualmente, a descoberta e a atribuição de sentido aos conteúdos estudados, resultando em produto final apto à edificação elevada da própria trajetória e identidade.

Em síntese crítica, entendendo-a como uma metodologia não apenas reativa, mas ativa e propositiva ante ao quadro educacional brasileiro, permeado pelas deficiências apontadas pelo PISA, ela pode contribuir para alunas e alunos praticarem a inteligência emocional, enunciada no aforismo "conhece-te a ti mesmo", do filósofo ateniense Sócrates (c. 469-399 a.C.), em que a verdade pode ser buscada no próprio ser humano e no autocontrole, na identificação das próprias fraquezas e sem os ásperos e desgastantes julgamentos característicos da educação estritamente formal. Por sinal, o método socrático de perguntas e respostas - frequente nas atividades da AP - pode proporcionar a possibilidade de identificação de um lugar de fala e, mesmo, a necessidade, da mesma maneira, de colocar-se na ótica e na visão do outro, desenvolvendo a empatia, e neste processo de conhecimento do outro, desenvolver o próprio conhecimento e autocontrole, alcançando maior clareza de objetivos em momentos de profundas incertezas e desafios que se afiguram no presente.

RC: 91806

Disponível em: https://www.nucleodoconhecimento.com.br/educacao/programainternacional 
Por meio dessas ações supõe-se que alunas e alunos desenvolvam, correspectivamente, a literacia enquanto capacidade de uso da leitura para habilidades cotidianas, além do controle e equilíbrio na expressão, percebendo-se como sujeito e objeto do conhecimento, motivando-se em face dos conteúdos estudados e identificando as dimensões afetivas - embora não únicas - do processo pedagógico, adentrando a um espectro de maior humanização do saber. São oportunidades para que os discentes possam também colher benefícios na gestão do tempo - mobilizando diferentes recursos cognitivos em favor da aprendizagem alcançando maior produtividade pelo desenvolvimento de crescente autonomia, entregando-se e integrando-se no conhecimento com maior segurança acadêmica e pessoal.

$\mathrm{Na}$ AP, ao lado da ousadia no ato de aprender, por meio desse autoconhecimento espera-se também que alunas e alunos, em patamar de resiliência emocional, alcancem o desenvolvimento da cautela - no entendimento maior do que é o próprio ser humano - face às manifestações comportamentais, disciplinando-se no ínterim da oportunidade de pensar a si mesmo, concatenando-se à reflexão acerca da melhoria de quadros sociais insatisfatórios e, mesmo, pela busca de soluções para os problemas de ordem transindividual e coletiva por meio de debates e discussões, que se tornam ocasiões se superação de crises (conscientizando-se que estas são sempre transitórias), o que se converte em habilidade de valor para a alteridade e, igualmente, para o mundo do trabalho contemporâneo.

Para os docentes, enquanto mediadores, há valiosa oportunidade para melhor conhecer suas alunas e alunos, materializando no bojo de uma educação que clama (também) por afetividade o aforismo aristotélico que nesse processo, é preciso educar não apenas mentes, mas, igualmente, corações. Nessa tarefa, a paciência e resiliência - sobretudo, em face da descrença de gestores e direção - é fundamental aos professores, especialmente porque alguns estudantes que se mostram resistentes ao processo educacional ou com dificuldades pedagógicas e disciplinares, não raro, por meio das sementes aparentemente infrutíferas que lhe 
são lançadas no presente, somente no futuro provam que elas germinam, nele frutificando substanciosamente como indivíduos responsáveis e cidadãos prestantes.

Nessa tarefa, por meio do diálogo e de uma postura propositiva, será importante motivar as alunas e alunos para a AP, supervisionando as relações estabelecidas para que não se desenvolva nenhum tipo de bullying, despertando a reflexão individual sobre a trajetória de caminhar incessantemente em direção ao aprendizado, bem como no âmbito coletivo engendrando a solidariedade e o ambiente acolhedor enquanto valor imprescindível à educação atual, que revelando grande dimensão e vicissitude afetiva, necessita acolher e integrar a todos.

As atividades da AP recentemente evidenciaram-se nos fóruns de comunicação remota de estudantes em ambientes virtuais - inclusive, com grande repercussão para as discussões relacionadas ao ensino não presencial e EaD, em debates que não caberiam neste artigo - e em nossa experiência, muito observadas por meio das TIC após a Resolução da Secretaria da Educação de 18 de Março de 2020, que homologou a Deliberação CEE n 177/2020, do Conselho Estadual de Educação do Estado de São Paulo (SÃO PAULO, 2020b), adequando os calendários escolares, e, em especial, após o Decreto Estadual n 64.864, de 16 de Março de 2020, que no âmbito paulista, reconhecendo o estado de calamidade pública ao longo das ações de combate e prevenção à pandemia do corona vírus (SÃO PAULO, 2020a), declarada em 11 de Março do mesmo ano pela Organização Mundial de Saúde, atingindo todo o mundo, determinou a suspensão das aulas na rede pública de ensino, causando ambiente de quarentena e isolamento social[7].

Por derradeiro, reitere-se que o uso de novas tecnologias, obviamente, pode auxiliar na prática pedagógica, mas não substitui o papel e a responsabilidade do professor nas orientações e segurança relacionadas aos conteúdos ministrados, advertindo-se que o uso em excesso da AP e de quaisquer outras metodologias isoladamente, pode trazer paradoxalmente resultados deletérios, tornando a aula igualmente 
desinteressante por sugerir descompromisso do docente com os temas relacionados à sua profissão e missão.

\section{REFERÊNCIAS}

ALTOÉ, L. Ensino de História à luz da BNCC. Rio de Janeiro: MultiRio, ed. 13, nov. 2019. Disponível em: <http://www.multirio.rj.gov.br/index.php/leia/reportagensartigos/reportagens/15310-ensino-de-hist\%C3\%B3ria-\%C3\%A0-luz-da-bncc>. Acesso em: 17 Mar. 2020.

BASE NACIONAL CURRICULAR COMUM. Brasília: Ministério da Educação. 2017.

<http://portal.mec.gov.br/index.php?option=com_docman\&view=download\&alias=79 601-anexo-texto-bncc-reexportado-pdf-2\&category_slug=dezembro-2017pdf\&ltemid=30192>. Acesso em: 18 Mar. 2020.

BORGES, V. P. O que é História. São Paulo: Brasiliense, ed. 2, reimp. 8, p. 85, 2003.

BRASIL. Lei no 9394, de 20 de dezembro de 1996. Estabelece as diretrizes e bases da educação nacional. Brasília: Palácio do Planalto, 1996. Disponível em: <http://portal.mec.gov.br/index.php?option=com_docman\&view=download\&alias=79 601-anexo-texto-bncc-reexportado-pdf-2\&category_slug=dezembro-2017pdf\&ltemid=30192>. Acesso em: 18 Mar. 2020.

BRASIL. Medida Provisória no 934, de 01 de abril de 2020. Estabelece normas excepcionais sobre o ano letivo da educação básica e do ensino superior decorrentes das medidas para enfrentamento da situação de emergência de saúde pública de que trata a Lei $n^{\circ}$ 13.979, de 06 de fevereiro de 2020. Brasília: Congresso Nacional, 2020.

Disponível

em:

<https://www.congressonacional.leg.br/materias/medidas-provisorias/-/mpv/141349>. Acesso em: 01 abr. 2020. 
BUENO, F. da S. Minidicionário da Língua Portuguesa. São Paulo: FTD, ed. 2, p. 864, 2007.

CASCARDO, J. Competências e habilidades no ensino: o que são e como aplicá-las? São Paulo: Par - Plataforma Educacional, 2020. Disponível em: <https://www.somospar.com.br/competencias-e-habilidades/>. Acesso em: 24 Mar. 2020.

CRANE, G. Thucydides and the Ancient Simplicity: The Limits of Political Realism. Berkeley, Los Angeles, London: University of California Press, 1998. Disponível em: $<$ https://publishing.cdlib.org/ucpressebooks/view?docld=ft767nb497\&chunk.id=intro\& toc. depth=1\&toc.id=intro\&brand=ucpress $>$. Acesso em: 16 Mar. 2020.

CROUCH, C. H.; MAZUR, E. Peer Instruction: Ten years of experience and results. American Journal of Physics. College Parks: American Association of Physics, vol. 69, ㄲo 09, p. 970-977, set. 2001. Disponível em: <https://sswm.info/sites/default/files/reference_attachments/CROUCH\%20and\%20M AZUR\%202001\%20Pee\%20Instruction\%20Ten\%20Years\%20of\%20Experience\%20 and\%20Results.pdf>. Acesso em: 22 Mar. 2020.

FERREIRA, J. P. M. H.; FERNANDES, L. E. O. Nova História Integrada. Campinas: Companhia da Escola, ed. 1, p. 577, 2005.

FRAZÃO, D. Tucídides. Historiador da Grécia Antiga. São Paulo: E-biografias, ed. 14, nov. 2019. Disponível em: <https://www.ebiografia.com/tucidides/>. Acesso em: 25 Mar. 2021.

INSTITUTO NACIONAL DE ESTUDOS PEDAGÓGICOS ANÍSIO TEIXEIRA. Programa Internacional de Avaliação de Estudantes (PISA). Brasília: Ministério da Educação, 2019. Disponível em: <http://portal.inep.gov.br/pisa>. Acesso em: 24 Mar. 2020. 
JOANILHO, A. L. História, política e sociedade. Curitiba: IESDE Brasil, p. 212, 2009.

ORGANIZATION FOR ECONOMIC COOPERATION AND DEVELOPMENT. About. Paris, 2020. Disponível em: <http://www.oecd.org/about/>. Acesso em: 18 fev. 2020.

PRADO, J. P. Manual para implantação do ensino não presencial na Educação Básica: Um material objetivo para auxiliar advogados e gestores que atuam na educação. São Paulo: Jota, ed. 11 abr. 2020. Disponível em: $<$ https://www.jota.info/opiniao-e-analise/colunas/regulacao-e-novastecnologias/manual-juridico-para-implantacao-do-ensino-nao-presencial-naeducacao-basica-11042020>. Acesso em: 12 abr. 2020.

PORTAL EDUCAÇÃO. História enquanto disciplina. São Paulo [s. d.]. Disponível em: <https://siteantigo.portaleducacao.com.br/conteudo/artigos/educacao/historiaenquanto-disciplina/24227>. Acesso em: 16 Mar. 2020.

SCHLEICHER, A. Insights and interpretation: PISA 2018. Paris: Organization for Economic Cooperation and Development. 2018. Disponível em: <https://www.oecd.org/pisa/PISA\%202018\%20Insights\%20and\%20Interpretations\%2 OFINAL\%20PDF.pdf>. Acesso em: 15 Mar. 2020.

SCHMIDT, J. P. Commons-based peer production and education. Short essay for the free culture research workshop. Cambridge, Boston: Harvard University, Berkman Klein Center, 23 out. 2009. Disponível em: $<$ https://cyber.harvard.edu/fcrw/sites/fcrw/images/Schmidt_Education_FreeCulture_2 50ct2009.pdf>. Acesso em: 18 Mar. 2020.

SÃO PAULO (Estado). Decreto no 64.864, de 16 de março de 2020. que dispõe sobre a adoção de medidas adicionais, de caráter temporário e emergencial, de prevenção de contágio pelo COVID-19 (Novo Coronavírus), e dá providências correlatas, 2020a. São Paulo: Palácio dos Bandeirantes. Disponível em: 
<https://www.saopaulo.sp.gov.br/wp-content/uploads/2020/03/decreto-64864.pdf>. Acesso em: 23 Mar. 2020.

SÃO PAULO (Estado). Resolução SEDUC, de 18 de março de 2020. que homologou a Deliberação no CEE no 177/2020, do Conselho Estadual de Educação do Estado de São Paulo, 2020b. São Paulo: Diretoria de Ensino Centro. Disponível em: <https://decentro.educacao.sp.gov.br/resolucao-seduc-de-18-3-2020/>. Acesso em: 27 Mar. 2020.

TEIXEIRA, A. Condições para a reconstrução educacional brasileira. Revista Brasileira de Estudos Pedagógicos. Rio de Janeiro, v. 18, № 49, p. 3-12, 1953. Disponível em: <http://www.bvanisioteixeira.ufba.br/artigos/condicoes.html>. Acesso em: 24 Mar. 2020.

VIGGIANO, G. 3 pontos para entender por que o Brasil evoluiu (mas não muito) em educação: Segundo relatório PISA 2018, desigualdade, desvalorização do professor e atmosfera ruim entre os alunos, são os fatores que mais prejudicam o aprendizado. Galileu: Rio de Janeiro, ed. 04 Dez 2019. Disponível em: $\quad$ https://revistagalileu.globo.com/Sociedade/noticia/2019/12/3-pontos-paraentender-por-que-o-brasil-evoluiu-mas-nao-muito-em-educacao.html>. Acesso em: 16 Mar. 2020.

\section{APÊNDICE - REFERÊNCIA DE NOTA DE RODAPÉ}

2. Com sede no Château de la Muette, em Paris, França, por convenção internacional foi criada em 30 de Setembro de 1961 a Organização para a Cooperação e Desenvolvimento Econômico (OCDE), e partir daí permitindo a adesão de países não europeus, sucedeu jurídica e institucionalmente a antiga Organização para a Cooperação Econômica Europeia, existente desde 1948. Na sua conformação estrutural, contou com o decisivo concurso do economista francês Robert Marjolin (1911-1986) - também amplamente envolvido com a então Comunidade Económica Europeia -, defendendo em âmbito principiológico os

RC: 91806

Disponível em: https://www.nucleodoconhecimento.com.br/educacao/programainternacional 
valores da democracia e economia de mercado no bojo das diretrizes do Plano Marshall - idealizado pelo general norte-americano George Marshall (1880-1959) -, que objetivava a recuperação econômica dos países europeus destruídos na Segunda Guerra Mundial (1939-1945) e que impediu o avanço geopolítico da União das Repúblicas Socialistas Soviéticas na região no período histórico conhecido como Guerra Fria (1939-1991). Especula-se nos últimos anos diferentes possibilidades de adesão do Brasil à OCDE. Cf. ORGANIZATION FOR ECONOMIC COOPERATION AND DEVELOPMENT (2020).

3. Oriunda da Língua Inglesa, a expressão mainstream possui o significado básico e primeiro de "convencional" e "objetivo final". Contudo, sobretudo, no pensamento econômico e naquele que é norteador e direcionado para a formulação de políticas públicas, vem adquirindo o sentido de "corrente principal", demonstrando o conjunto das ideias predominantes em determinado setor do conhecimento.

4. A partir da BNCC, na perspectiva de determinar as aprendizagens essenciais para a formação do estudante em todos os segmentos educacionais, Cascardo (2020) nos explica que, indicada pelo desempenho, a competência deve ser compreendida no bojo dos atributos relacionados à aptidão e mobilização de recursos para resolução de problemas, para bem fazer, para o convívio e eficaz encaminhamento de situações da vida cotidiana.

5. Na mesma orientação a partir da BNCC, Cascardo (2020) igualmente esclarece o entendimento de habilidade, colocando-a como "a aplicação prática de uma determinada competência para resolver uma situação complexa", um saber fazer (com planejamento e execução), como nos atos de escrever e ler, aos quais deve somar-se a própria compreensão do texto envolvido no processo.

6. Prado (2020), por oportuno, nos esclarece que o ensino não presencial se trata de uma situação momentânea e emergencial, sem ganho de escala, adotada face à interrupção das atividades presenciais - como ocorreu na pandemia do coronavírus que suspendeu as aulas por todo o mundo -, representando a possibilidade de 
"entrega das atividades presenciais em ambiente virtual", enquanto que no EaD já existe uma estrutura montada a partir da rede mundial de computadores, a Internet, permitindo ganho de escala, com "aulas assíncronas e um aparato de tutoria e outros serviços para individualizar o atendimento".

7. No mesmo sentido foi a Medida Provisória o 934, de 01 de abril de 2020, editada pelo Poder Executivo federal, estabelecendo normas excepcionais sobre o ano letivo da educação básica e do ensino superior decorrentes das medidas para enfrentamento da situação de emergência de saúde pública de que trata a Lei no 13.979, de 06 de Fevereiro de 2020. Pelo texto, mantendo a carga horária anual de oitocentas horas, ela flexibiliza a exigência mínima de duzentos dias letivos, contida no inciso I do caput e no $\S 1^{\circ}$ do artigo 24 e no inciso II do caput do artigo 31 da LDB. Cf. BRASIL, 2020.

Enviado: Março, 2021.

Aprovado: Julho, 2021. 